\title{
$\mathrm{Fe}$ 계 나노결정립 분말과 페라이트 복합체의 전자파 흡수특성
}

구숙경 · 이민혁 · 문병기 $\left.\right|^{a}$ 송용설 ${ }^{b}$ 손근용* · 박원욱

인제대학부 나노공학부, ${ }^{a}$ 한국기계연구원부설 재료연구소, ${ }^{b}$ (주)아모센스

\section{Electromagnetic Wave Absorption Behavior of a Fe-based Nanocrystalline Alloy mixed with a Ferrite Powder}

\author{
S. K. Koo, M. H. Lee, B. G. Moon ${ }^{a}$, Y. S. Song ${ }^{b}$, K. Y. Sohn* and W. W. Park \\ School of Nano Engineering, Inje University, 607 Obang-dong, Gimhae, Gyeongnam 621-749, Korea \\ ${ }^{a}$ Advanced Materials Research Division, Korea Institute of Materials Science, \\ 531 Changwondaero, Changwon, 641-831, Korea \\ ${ }^{b}$ Research Institute, Amosense Co., 185-1 Sucham-ri, Tongjin-eup, \\ Kimpo, Gyeongki-do 415-860, Korea
}

(Received May 16, 2008; Accepted July 10, 2008)

\begin{abstract}
The electromagnetic (EM) wave absorption properties of the $\mathrm{Fe}_{73} \mathrm{Si}_{16} \mathrm{~B}_{7} \mathrm{Nb}_{3} \mathrm{Cu}_{1}$ nanocrystalline powder mixed with 5 to $20 \mathrm{vol} \%$ of $\mathrm{Ni}-\mathrm{Zn}$ ferrites has been investigated in a frequency range from $100 \mathrm{MHz}$ to $10 \mathrm{GHz}$. Amorphous ribbons prepared by a planar flow casting process were pulverized and milled after annealing at 425 for 1 hour. The powder was mixed with a ferrite powder at various volume ratios to tape-cast into a $1.0 \mathrm{~mm}$ thick sheet. Results showed that the EM wave absorption sheet with $\mathrm{Ni}-\mathrm{Zn}$ ferrite powder reduced complex permittivity due to low dielectric constant of ferrite compared with nanocrystalline powder, while that with $5 \mathrm{vol} \%$ of ferrite showed relatively higher imaginary part of permeability. The sheet mixed with 5 vol\% ferrite powder showed the best electromagnetic wave absorption properties at high frequency ranges, which resulted from the increased imaginary part of permeability due to reduced eddy current.
\end{abstract}

Keywords : Electromagnetic wave absorption, Ni-Zn ferrite, Nanocrystalline powder

\section{1. 서 론}

최근 휴대전화, 디지털 카메라 둥 각종 전자 및 정보통신기기의 소형화 및 경량화에 따른 회로 부품 의 고집적화가 급속히 진전되면서, 이들로부터 발생 되는 불요 전자파로 인한 전자기기의 오작동 및 인 체 피해 등의 현상이 심각한 문제로 대두되고 있다. 이러한 전자파 간섭을 억제하기 위한 대책으로 박형, 경량의 고기능 전자파 흡수체의 개발이 필요하다[1-3]. 전자파 홉수체는 사용하고자 하는 주파수 대역에서 매질의 도전, 유전 및 자성 손실이 큰 재료를 이용하 여 입사된 전파에너지를 홉수하여 열로 변환함으로
써 전자파의 세기를 효과적으로 감쇄시킨다[4-5]. 현 재까지 $\mathrm{MHz} \mathrm{GHz}$ 대에서 사용되는 전자파 홉수체는 크게 자성손실을 이용한 홉수체와 유전손실을 이용 한 홉수체로 나누어진다. 특히, 자성손실 재료는 다 른 전자파 홉수체보다 고주파 대역에서 사용되며, 자 벽공명 및 자연공명에 기인한 자성손실을 이용한 것 으로 두께가 얇고 동작 주파수 범위가 넓은 장점이 있다. Finemet계 나노결정립 연자성재료는 10 15 $\mathrm{nm}$ 정도 크기의 미세한 $\alpha-\mathrm{Fe}(\mathrm{Si})$ 상의 결정립과 $\mathrm{Nb}$ 등이 농축된 비정질 입계상으로 구성되어 고주파 손실 이 적고, 포화자속밀도가 커서 얇은 두께로 우수한 특성을 나타낼 뿐 아니라 $\mathrm{Fe}$ 계 비정질 합금에 비해

*Corresponding Author : [Tel : +82-55-320-3714; E-mail : ksohn@inje.ac.kr] 
우수한 투자율을 가진다. 연자성 페라이트는 부피와 중량이 커서 홉수체 제작시 홉수체의 두께가 두꺼우 나, 고투자율을 가지고, 가격이 저렴하며 저주파에서 특성이 우수한 장점이 있다[6-7]. 본 연구에서는 $\mathrm{Fe}$ 계 나노결정립 분말을 시트 형태로 제조하여, 수 $\mathrm{MHz}-\mathrm{GHz}$ 의 주피수범위에서 페라이트 첨가량의 변 화에 따른 시트의 유전율 및 투자율 둥 전자파 흡수 특성에 미치는 영향을 조사하였다.

\section{2. 실험방법}

본 연구에서는 Vacuum Schmelze 사에서 제조한 $\mathrm{Fe}_{73} \mathrm{Si}_{16} \mathrm{~B}_{7} \mathrm{Nb}_{3} \mathrm{Cu}_{1}(\mathrm{at} \%)$ 비정질 리본(두께 20-22 $\mu \mathrm{m}$ ) 을 $425^{\circ} \mathrm{C}$ 에서 1 시간 동안 예비 열처리한 후 pulverizing 과 attrition milling 을 통해 편상화된 분 말을 제조하였다. 제조된 분말의 분급을 통해 270 mesh 이하의 입자크기를 가진 분말을 선택한 뒤, 고 순도 질소 분위기에서 $550^{\circ} \mathrm{C}$ 에서 1시간 결정화 열처 리를 하였다. 나노결정립 분말의 전자파 홉수특성에 미치는 페라이트의 영향을 평가하기 위해 $\mathrm{Fe}$ 계 나노 결정립 분말을 모재.료로 $\mathrm{Ni}-\mathrm{Zn}$ 페라이트 분말 $(\mathrm{d}<-6.5$ $\mu \mathrm{m})$ 을 각각 $5,10,15,20 \mathrm{vol} \%$ 첨가한 후, 교반기 를 통해 $120 \mathrm{rpm}$ 으로 2 분간 바인더와 경화제를 혼 합하였다. 슬러리 형태가 된 분말을 테이프캐스팅 (tape casting)을 통해 평균 $1.0 \mathrm{~mm}$ 두께의 시트를 제작하였으며, 오븐을 이용하여 $100^{\circ} \mathrm{C}$ 에서 1 시간 동 안 건조 열처리 한 후, 실온에서 24시간 건조하였다.

분말의 입도 측정을 위해 고분해능 주사전자현미 경(FE-SEM)을 이용하였으며, 시료의 전자파홉수특성 을 평가하기 위해 $70^{\circ} \mathrm{C}$ 에서 압연과정을 거쳐 흡수
시트의 두께를 평균 $0.3 \mathrm{~mm}$ 로 제작하였다. 이 전자 파 흡수체를 펀치를 이용하여 외경 $7 \mathrm{~mm}$, 내경 3 $\mathrm{mm}$ 의 토로이드(toroid) 형태의 시편을 만든 다음, 밀 도를 측정하여 균일도(평균밀도: $3.82 \mathrm{~g} / \mathrm{cm}^{3}$, 오차: $\pm 0.3 \%$ 이내)를 확인한 뒤 Network Analyzer(Agilent 사 제품 $\mathrm{N} 5230 \mathrm{~A}$ )를 이용하여 2-port coaxial 방법으 로 $\mathrm{S}$ 파라미터, 투자율, 유전율을 $100 \mathrm{MHz} 10 \mathrm{GHz}$ 의 범위에서 측정하였으며, 이로부터 전자파 홉수능을 비교, 분석하였다.

\section{3. 실헙결과 및 고찰}

\section{1. 투자율 및 유전율의 변화}

나노결정립 분말과 $\mathrm{Ni}-\mathrm{Zn}$ 페라이트의 분말 입자들 을 관찰한 결과를 그림 1에 나타내었다. 그림 1(a)는 나노결정립 분말의 SEM조직으로서, 초기두께가 약 $20 \mu \mathrm{m}$ 이었던 것이 밀링 후 최종 두께가 대부분 2 $\mu \mathrm{m}$ 이하로 감소된 것으로 관찰되었다. 그림 $1(\mathrm{~b})$ 는 이 분말을 $550^{\circ} \mathrm{C}$ 에서 1 시간 결정화 열처리 한 뒤의 $\mathrm{TEM}$ 조직 관찰결과로서 비정질 기지내에 생성된 결 정립의 크기는 약 $12-18 \mathrm{~nm}$ 이었다. 한편, $\mathrm{Ni}-\mathrm{Zn}$ 페라 이트 분말 입자는 그림 1(c)에 나타낸 바와 같이 크 기가 약 1.1 6.3 $\mu \mathrm{m}$ 의 범위에 다양하게 분포되어 있는 것으로 나타났다.

나노결정립 분말의 페라이트 첨가에 따른 전자파 흡수시트의 복소투자율 $\left(\mu_{\mathrm{r}}=\mu^{\prime}-\mathrm{j} \mu_{\mathrm{r}}{ }^{\prime}\right)$ 의 주파수 분산 특 성을 그림 2에 나타내었다. 여기서 투자율의 실수부 $\left(\mu_{\mathrm{r}}{ }^{\prime}\right)$ 는 실제적으로 전자파 에너지에 반응하는 함수를 나타내며, 투자율의 허수부 $\left(\mu_{r}{ }^{\prime}\right)$ 는 자성 손실에 관여 하는 손실 함수를 의미한다. 그림 2 에서 알 수 있는

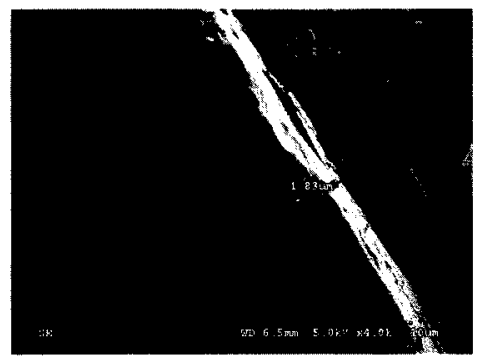

(a)

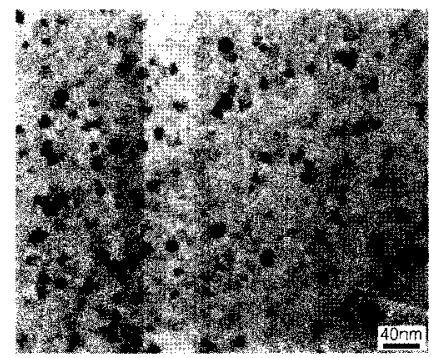

(b)

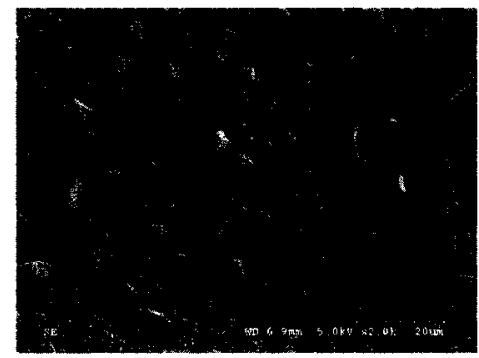

(c)

Fig. 1. (a) SEM micrograph showing the thickness of the Fe-based nanocrystalline powder used in this study, (b) TEM micrograph of the nanocrystalline ribbon after crystallization treatment at $550^{\circ} \mathrm{C}$ for 1 hour and (c) Appearance of $\mathrm{Ni}-\mathrm{Zn}$ ferrite powder. 


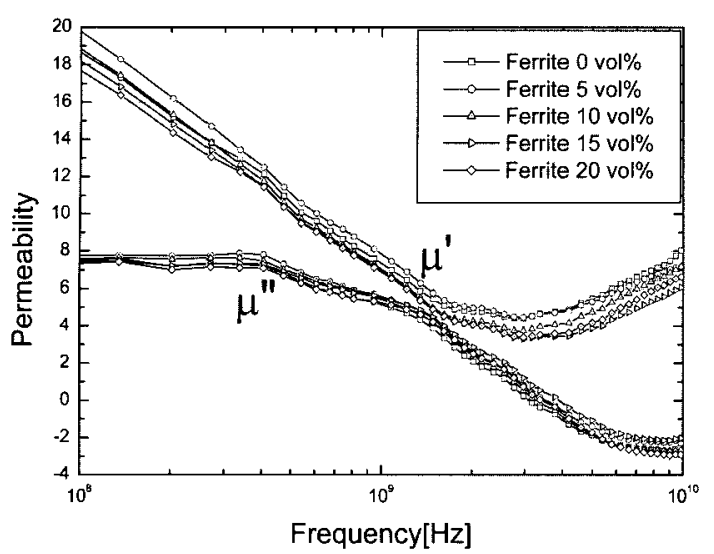

Fig. 2. The complex relative permeability curves of $\mathrm{Fe}_{73} \mathrm{Si}_{16} \mathrm{~B}_{7} \mathrm{Nb}_{3} \mathrm{Cu}_{1}$ alloy mixed with $0 \sim 20$ vol\% ferrite powder.

바와 같이 투자율은 인가 주파수가 증가함에 따라 실 수부와 허수부 모두 감소하는 경항을 나타내었다. 페 라이트 첨가량에 따른 효과를 살펴보면, 투자율 실수 부는 $3 \mathrm{GHz}$ 이하의 주파수 대역까지는 $5 \mathrm{vol} \%$ 페라 이트를 첨가한 시트의 투자율이 다소 높게 나타넜으 나, 그 이상의 주파수에서는 페라이트 첨가량의 증가 에 따라 투자율이 감소하였다. 페라이트의 투자율은 Finemet계 연자성재료에 비해 낮으므로 페라이트의 함량이 증가함에 따라 투자율 실수부가 감소하리라 는 것은 쉅게 예측할 수 있다[8-9]. 투자율 허수부의 변화를 살펴보면, 주파수에 따라 다소의 분산은 있으 나, 대체로 페라이트를 함유하지 않은 시료에 비해 페라이트를 함유하고 있는 시료의 허수부투자율이 높 으며, 특히 $5 \mathrm{vol} \%$ 페라이트의 허수부투자율이 다소 높게 나타났다. 허수부투자율의 중가는 전자파흡수능 의 향상과 관계되며, 페라이트 함량이 증가함에 따라 허수부투자율이 증가하는 이유는 시트의 비저항의 증 가에 따른 와전류의 감소에 기인한 것이라고 할 수 있다.

그림 3 은 페라이트 분말의 첨가에 따른 복소유전 율 $\left(\varepsilon_{\mathrm{r}}=\varepsilon_{\mathrm{r}}^{\prime}-\mathrm{j} \varepsilon_{\mathrm{r}}{ }_{\mathrm{r}}\right)$ 의 주파수 분산 특성이다. 유전율 실수부 역시 전자파 에너지에 실제적으로 반응하는 함수이 며, 허수부는 유전 손실과 같은 손실 함수를 의미한 다. 유전율 실수부와 허수부 모두 페라이트를 첨가 하지 않은 시트의 유전율이 첨가한 시트의 유전율 보다 높게 나타났으며, 페라이트 첨가량이 증가함에 따라 유전율이 감소하는 것으로 나타났다. 복소유전

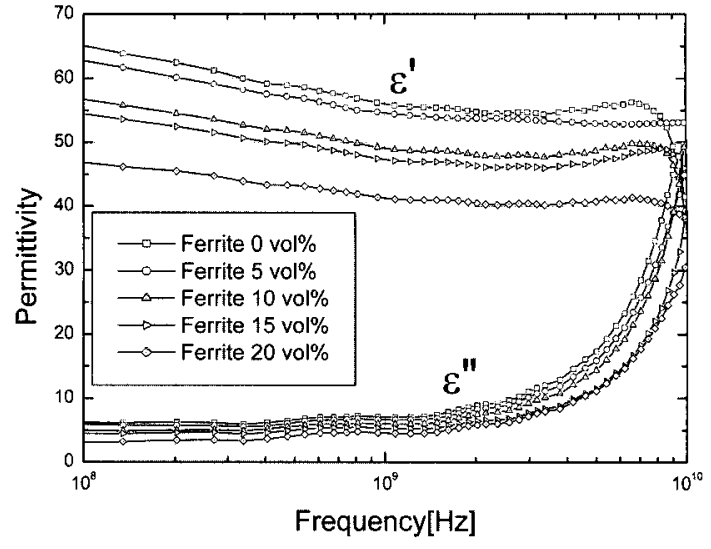

Fig. 3. The complex relative permittivity curves of $\mathrm{Fe}_{73} \mathrm{Si}_{16} \mathrm{~B}_{7} \mathrm{Nb}_{3} \mathrm{Cu}_{1}$ alloy mixed with $0 \sim 20$ vol\% ferrite powder.

율의 실수부가 감소하는 이유는 $\mathrm{Fe}$ 나노결정립 합 금에 비하여 상대적으로 유전상수 값이 작은 페라 이트의 분율이 증가했기 때문이다. 복소유전율의 허 수부는 유전손실을 나타내는뎨, 이는 인가된 전기장 에 대한 감쇄를 나타내며, 일반적으로 주파수가 증 가할수록 그림 3에 나타낸 바와 같이 증가한다. 이 유전 손실은 두 가지 요인에 기인한다고 알려져 있 다[10-11]. 첫째로, 영구쌍극자 또는 유도쌍극자와 관련된 완화(relaxation)에 기인하는 것으로서 이들 이 인가된 주파수의 변화속도에 충분히 반응하지 못 하기 때문에 발생한다. 둘째는 원자, 이온 또는 전 자들의 회전이나 진동에 의해 발생하는 공명 (resonance)에 기인하는뎨 이는 특정 홉수주파수 주 변에서 발생한다. 여기에서는 유전율이 상대적으로 낮은 페라이트의 함량이 증가함으로써 고주파로 갈 수록 쌍극자들의 완화효과가 더 증가했다고 생각할 수 있다.

\section{2. 전자파 흡수ㅇㅠㅠㅇㅢ 변화}

그림 4 6은 페라이트 첨가에 따른 흡수체의 전자 파 흡수율(Power Loss)을 Network Analyzer를 이 용한 coaxial 방법으로 측정한 결과이다. 여기서, $\mathrm{S}_{11}$ 은 전자파 입사에 대한 반사 에너지 비의 항으로, $\mathrm{S}_{21}$ 은 전자파 입사에 대한 투과 에너지 비의 항으로 식(1), (2)와 같이 표시되며, 전자파 흡수율은 $\mathrm{R}$ 과 $\mathrm{T}$ 의 각각 제곱의 합과의 차에 의해 식(3)으로 얻어진 다[12-13]. 


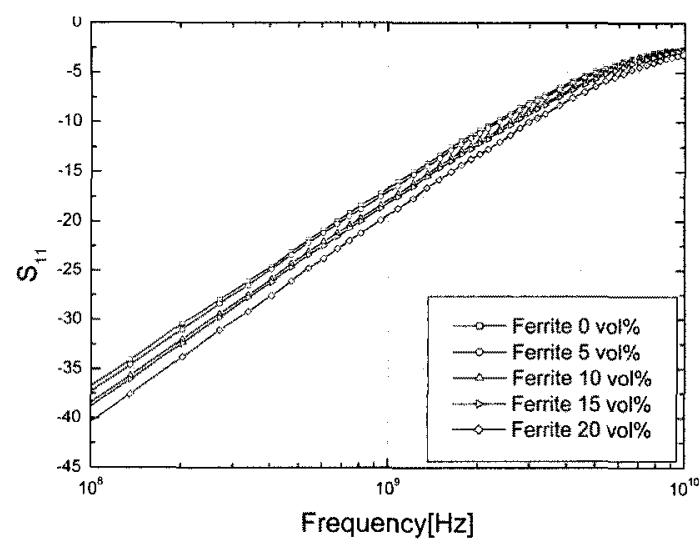

Fig. 4. Variations of $\mathrm{S}_{11}$ of $\mathrm{Fe}_{73} \mathrm{Si}_{16} \mathrm{~B}_{7} \mathrm{Nb}_{3} \mathrm{Cu}_{1}$ alloy powder sheet mixed with $0 \sim 20$ vol $\%$ ferrite powder.

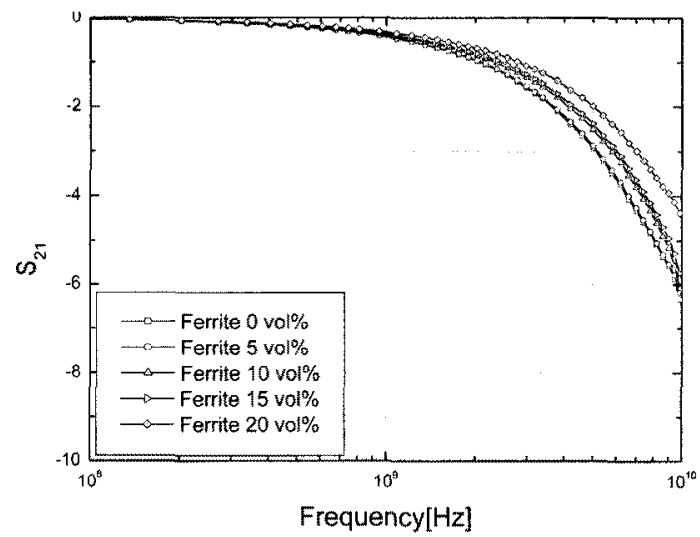

Fig. 5. Variations of $\mathrm{S}_{21}$ of $\mathrm{Fe}_{73} \mathrm{Si}_{16} \mathrm{~B}_{7} \mathrm{Nb}_{3} \mathrm{Cu}_{1}$ alloy powder sheet mixed with $0 \sim 20$ vol \% ferrite powder.

$$
\begin{aligned}
& S_{11}=20 \cdot \log R,\left[R=\frac{\text { Reflected Power }}{\text { Incident Power }}\right] \\
& S_{21}=20 \cdot \log T,\left[T=\frac{\text { Transmittet Power }}{\text { Incident Power }}\right]
\end{aligned}
$$

$$
\text { Power Loss }=1-\left(|R|^{2}+|T|^{2}\right)
$$

그림 4 의 $\mathrm{S}_{11}$ 에 대한 측정졀과로부터 주파수가 높 아짐에 따라 페라이트를 첨가하지 않은 시료나 첨가 한 시료 모두 입사에 대한 반사에너지 $\left(\mathrm{S}_{11}\right)$ 가 증가함 을 알 수 있다. 이 중, 페라이트를 첨가하지 않은 시 료의 반사에너지 값이 가장 크게 나타났으며, 페라이 트 첨가량이 증가할수록 반사에너지가 감소하는 것 으로 관찰되었다. 한편, 입사에 대한 투과에너지 비 를 나타내는 $\mathrm{S}_{21}$ 의 경우(그림 5), 페라이트를 첨가하 지 않은 시료와 $5 \mathrm{vol} \%$ 페라이트 첨가시료의 전자

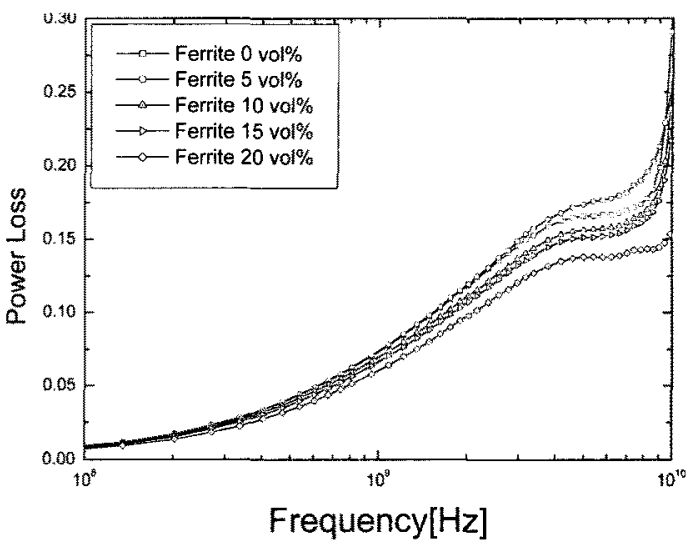

Fig. 6. $\mathrm{EM}$ wave absorption curves of $\mathrm{Fe}_{73} \mathrm{Si}_{16} \mathrm{~B}_{7} \mathrm{Nb}_{3} \mathrm{Cu}_{1}$ alloy powder sheet mixed with $0 \sim 20$ vol\% ferrite powder.

파 투과비율이 거의 같은 비율로 가장 낮게 나타나 는 것으로 관찰되었으며, 전체적으로 페라이트 첨가 량이 증가함에 따라 전자파 투과비율이 증가하는 것 으로 나타났다. 흡수율이 높기 위해서는 위에 제시한 식 (3)에 따라 $S_{11}$ 및 $S_{21}$ 의 값이 모두 낮아야 한다.

그림 6은 그림 4와 그림 5의 결과로부터 식(3)을 이용하여 계산한 전자표 흡수율을 폐라이트의 함량 및 주파수의 함수로 나타낸 것이다. 이 그림에서, $1 \mathrm{GHz}$ 의 주파수 이하에서는 나노결정립 분말시트가 페라이트 함량의 영항을 크게 받지 않으나, 그 이상 에서는 페라이트 함량의 변화에 따라 전자파흡수능 이 다소 달라지는 것을 확인할 수 있다. 이 경우, 페 라이트 분말을 $5 \mathrm{vol} \%$ 첨가한 시트의 흡수능이 가 장 높게 나타났으며, 이 후에는 페라이트의 함량이 증가함에 따라 전자파흡수능이 감소하는 것을 알 수 있다. 이 결과는 페라이트를 첨가하지 않은 시료와 비교하여 $5 \mathrm{vol} \%$ 첨가한 시트의 경우에, 반사에너지 를 나타내는 $S_{11}$ 의 감소효과가 투과에너지를 나타내 는 $\mathrm{S}_{21}$ 의 증가효과에 비해 상대적으로 크기 때문인뎨, 이 변화량의 절대값을 비교하면 $7 \mathrm{GHz}$ 의 경우 $\Delta S_{11}$ 이 $\Delta S_{21}$ 에 비해 약 3 배정도 큰 것으로 확인되었다. 즉, $5 \mathrm{vol} \%$ 의 페라이트를 첨가함으로써 반사되는 전 자파에너지 $\left(\mathrm{S}_{11}\right)$ 는 크게 감소한 반면, 투과되는 전자 파에너지 $\left(\mathrm{S}_{21}\right)$ 는 약간만 증가했기 때문이다. 이러한 전자파 홉수능은 자성손실과 유전손실의 두 가지 인 자에 크게 영항을 받는다. 페라이트를 $5 \mathrm{vol} \%$ 첨가 한 경우, 와전류의 감소에 마른 허수부투자율의 증가 효과가 시트내의 유전율 감소에 따른 흡수율저하효 
과 보다 크기 때문으로 판단된다. 그러나, 페라이트 를 $10 \mathrm{vol} \%$ 이상 첨가한 경우는 페라이트 함량 증 가에 따른 $\mathrm{Fe}$ 계 나노결정립 전자파흡수시트의 유전 율 감소효과가 와전류 감소에 의한 허수부투자율 증 가효과 보다 크기 때문에 페라이트를 첨가하지 않은 시트에 비해 흡수율이 떨어지는 것으로 풀이된다. 이 결과로 보면, 페라이트 $5 \mathrm{vol} \%$ 를 함유하는 $\mathrm{Fe}$ 나노 결정립 시료의 전자파흡수 특성은 유전율 변화의 영 향보다는 투자율 변화의 영향이 더 클 것으로 판단 되었다.

\section{4. 결 론}

$\mathrm{Fe}_{73} \mathrm{Si}_{16} \mathrm{~B}_{7} \mathrm{Nb}_{3} \mathrm{Cu}_{1}(\mathrm{at} \%)$ 나노결정립 분말에 $\mathrm{Ni}-$ $\mathrm{Zn}$ 페라이트를 0 20 vol\% 첨가하여 제조한 분말시트 의 복소투자율, 복소 유전율, 전자파합수율을 평가한 결과는 다음과 같다.

1. 페라이트 첨가는 시트의 실수부 투자율을 감소 시킨 반면 허수부 투자율을 증가시켰으며, 특히 $5 \mathrm{vol} \%$ 페라이트가 첨가된 시트의 허수부 투자율을 증가시켰다. 이는 시트의 저항이 증가하여 와전류가 감소하였기 때문이다.

2. 나노결정립 분말에 페라이트를 첨가했을 경우 유전율은 실수부 및 허수부 모두 감소되었으며, 그 이유는 $\mathrm{Fe}$ 나노결정립 합금에 비하여 상대적으로 유 전상수가 낮은 페라이트 분말의 분율이 증가했기 때 문이다.

3. 나노결정립 분말시트의 전자파홉수율은 $5 \mathrm{vol} \%$ 페라이트를 첨가한 시트의 흡수율이 가장 높게 나타 났으며, 나머지는 페라이트의 함량이 증가함에 따라 다소 감소하였다. $5 \mathrm{vol} \%$ 페라이트를 첨가한 경우 흡수율이 증가한 이유는 페라이트의 소량 첨가에 의 해 전자파 에너지의 투과량 $\left(\mathrm{S}_{21}\right)$ 이 소폭 중가하기는 하였으나 반사량 $\left(\mathrm{S}_{11}\right)$ 은 크게 감소하였기 때문으로, 이 는 페라이트 분말의 분율 증가에 따른 유전율 감소
효과 보다 시료의 비저항 증가에 의한 와전류의 감 소효과가 상대적으로 크다는 것을 의미한다.

\section{감사의 글}

본 연구는 (주)아모센스의 2007NURI사업 산학협 력연구지원에 의해 수행되었으며, 이에 감사 드립니 다. 또한, (주)아모센스 권상균넘의 전자파 흡수특성 평가에 대한 도움에도 감사드립니다.

\section{참고문헌}

[1] S. Sugimoto, T. Maeda, D. Book, T. Kagotani, K. Inomata, M. Homma, H. Ota, Y. Houjou and R. Sato: J. Alloys. Comp., 330 (2002) 301.

[2] J. R. Liu, M. Itoh, T. Horikawa, M. Itakura, N. Kuwano and K. Machida: J. Appl. Phys., 37 (2004) 2737.

[3] T. H. Noh and J. B. Kim: J. Kor. Inst. Met \& Mater., 46 (2008) 44 (Korean).

[4] D. S. Li, T. H. Horikawa, J. R. Liu, M. Itoh and K. Machida: J. Alloys Compd., 408 (2006) 1429.

[5] H. J. Cho, E. K. Cho, Y. S. Song, S. K. Kwon, K. Y. Sohn and W. W. Park: Mater. Sci. Forum, 534 (2007) 1345.

[6] S. H. Hong, K. Y. Shon, W. W. Park, B. G Moon and Y. S. Song: J. Korean Powder Metall. Inst., 15 (2008) 18 (Korean).

[7] K. M. Lim, M. C. Kim, K. A. Lee and C. G. Park: J. Kor. Inst. Met \& Mater., 41 (2003) 180 (Korean).

[8] Y. Yoshizawa, S. Oguma and K. Yamauchi: J. Appl. Phys., 64 (1988) 6044.

[9] F. Mazaleyrat and L. K. Varga: J. Magn \& Magn Mater., 215-216 (2000) 253.

[10] http://en.wikipedia.org/wiki/permittivity\#Lossy_medium.

[11] McGraw-Hill: Encyclopedia of Physics, S. P. Parker (Ed.), 5th ed, New York (1983) 232.

[12] http://cp.literature.agilent.com/litweb/pdf/5965-7917E.pdf, Agilent Technical Report No.5965-7917E.

[13] A. Hosoe, K. Nitta, S. Inazawa, K. Yamada, T. Yoshisaka and K. Ikeda: SEI Tech. Rev., 54 (2002) 20. 